\title{
Article \\ A Pilot Study on the Quality of Sexual Life of Patients Receiving Home Palliative Care in Poland
}

\author{
Marcin Janecki ${ }^{1, * \mathbb{C}}$, Izabela Kaptacz ${ }^{1}$, Zuzanna Janecka $^{2}$ and Violetta Skrzypulec-Plinta ${ }^{3}$ \\ 1 Department of Palliative Medicine and Palliative Care, Medical University of Silesia in Katowice, \\ 40-752 Katowice, Poland; ikaptacz@gmail.com \\ 2 School of Medicine, Medical University of Silesia in Katowice, 40-752 Katowice, Poland; zuzia.janecka@op.pl \\ 3 Department of Reproductive Health and Sexology, Medical University of Silesia in Katowice, \\ 40-752 Katowice, Poland; skrzypulec-plinta@o2.pl \\ * Correspondence: janeckimarcin@op.pl
}

Citation: Janecki, M.; Kaptacz, I.; Janecka, Z.; Skrzypulec-Plinta, V. A Pilot Study on the Quality of Sexual Life of Patients Receiving Home Palliative Care in Poland. Sexes 2021, 2,174-182. https://doi.org/ $10.3390 /$ sexes 2020015

Academic Editors: David L. Rowland and Pawel Miotla

Received: 24 February 2021

Accepted: 15 April 2021

Published: 20 April 2021

Publisher's Note: MDPI stays neutral with regard to jurisdictional claims in published maps and institutional affiliations.

Copyright: (c) 2021 by the authors. Licensee MDPI, Basel, Switzerland. This article is an open access article distributed under the terms and conditions of the Creative Commons Attribution (CC BY) license (https:// creativecommons.org/licenses/by/ $4.0 /)$.

\begin{abstract}
Background: Quality of life, physical, psychic, and social functioning assessments in patients suffering from chronic, progressive, and incurable diseases are one of the most significant aims of the palliative care home teams. Sexuality and intimacy can be one of the most important elements of a person's life, even at the end of it. Unfortunately, there is very little interest in this topic among medical staff of palliative care units. The objective of the study: The aim of this study was to assess the health status, the quality of life, the quality of sexual life, and the recognition and resolution of sexual problems by the palliative care team in adult patients in the advanced stage of terminal illness, who were receiving home palliative care. Research methods: The study involved 342 adult patients in the advanced stage of incurable, progressive disease, covered by home palliative care in 15 facilities in Poland. A generic EuroQoL 5-Dimension 3-Level health and quality of life assessment questionnaire and a questionnaire developed by the researchers, including questions about sexual problems, were used in this prospective study. Results: The presented results are the part of the more extensive study. The assessment of health status and quality of life of the study patients showed that the evaluation was the lowest for performing ordinary daily activities. The quality of sexual life after diagnosis in more than half of the study patients has worsened. Almost half of the respondents felt that the palliative care team did not recognize or address their sexual concerns. Patients indicated nurses and physicians as the members of the palliative care team most helpful in identifying and addressing sexual concerns. Conclusions: Members of the palliative care team should receive training in communication with patients concerning their sexual life, their needs and expectations and have knowledge about options for obtaining specialized sexological care. It is necessary to prepare and validate simple tools that will facilitate the initiation of appropriate communication between patients and members of the medical staff. It will be important to conduct more detailed and targeted research on sexuality and intimacy in the Polish palliative care patient population.
\end{abstract}

Keywords: home palliative care; sexuality; sexual health

\section{Introduction}

The observed trend of morbidity and mortality due to malignant neoplasms in Poland constitutes a significant health problem, increasing the demand for palliative care for these patients. In 2018, 419 facilities provided home palliative care services in Poland and tens of thousands of patients were covered by home care [1].

The fear of death and dying makes it difficult for a large part of society to have honest conversations with terminally ill patients about prognosis, disease progression, and the foreseeable future [2]. Both the patient and the family require accurate and appropriately communicated information about the options for care and support in all fields of life-physical, psycho-spiritual, and social. Lack of information or false information limits the ability of patients to make important life decisions. Proper organization of 
care in the patient's home and engaging the members of his or her family members give the opportunity to start important conversations, express emotions, fulfill dreams, and accompany a terminally ill person in his or her last days [2]. This requires knowledge, time, and experience on the part of the team.

Sexuality and intimacy are one of the most important elements of human life, and physical intimacy and the desire for sexual expression is not reserved only for healthy people. Assessing the quality of sexual life should be one of the tasks for the palliative care team, but some patients, as well as some professionals, find it difficult to talk about it openly. Sexuality can be experienced and expressed in thoughts, fantasies, desires, beliefs, practices, and relationships.

Sexuality is affected by a number of biological, psychological, social, economic, political, cultural, and religious factors [3]. Holistic palliative care should involve the integral components of patient functioning in terms of sexual health, sexuality including intimacy, level of expectation, anticipated distress, and side effects associated with treatment. However, sexuality is an often-overlooked aspect in clinical practice, yet loss of sexual health can affect the overall quality of life (QoL) and well-being of the patient $[4,5]$.

The most common problems in cancer patients in terms of sexual functioning are loss of desire for sexual activity, problems achieving and maintaining an erection for men and pain during sexual intercourse for women [6]. Since most sexual problems will not go away, but will persist or even increase, early assessment of problems is important. Patient care should involve undertaking strategies to encourage them to talk, trying again at the next visit if they are reluctant to open, allowing time for them to get used to the topic, analyzing needs, and engaging their partners in the conversation [7]. However, there has been a weak focus on sexual health and intimacy in palliative care [8]. In many countries, including Poland, regardless of the great development of palliative home care services and standard assessment of patients' quality of life, there is a lack of standardized tools for sexual needs and problems recognition. In this situation, there is a need for creating an add-on simple questionnaire, which is sometimes prepared by individual teams and included in the standard QoL assessment tool. Moreover, it seems that these problems are not as frequently addressed as expected in daily practice by palliative care team members.

The aim of the study was to assess health status, general quality of life in connection with quality of sexual life, and recognition and solving of sexual problems by the palliative care team in adult patients in the advanced stage of terminal illness, covered by home palliative care.

\section{Materials and Methods}

The study group consisted of 342 adult White/Caucasian patients (60\% women and $40 \%$ men) in advanced stage of incurable, progressive disease, covered by home palliative care teams from 15 sites in Poland, located in 10 out of 16 provinces. The study protocol did not include any questions regarding sexual preferences or gender minority groups. No signals regarding barriers to palliative care in sexual or gender minorities were reported during the study whatsoever. The study was conducted from August 2017 to August 2018. Participation in the study was voluntary and anonymous. Patients with logical contact, after giving verbal consent to participate in the study, completed questionnaires on their own, and were assisted by family or the researcher if they had difficulty understanding the questions. Criteria for exclusion from the study were the presence of cognitive impairment or patient withdrawal of consent.

The study was approved by the Bioethics Committee at the Silesian Medical University in Katowice on 30 May 2017 (No. NNW/0022/KB/141/17). The findings are part of a broader research project.

The largest group was patients aged 61 to 70 years $(38.5 \%)$, followed by patients aged 71 to 79 years $(31.8 \%)$. Respondents were mostly resided in urban areas $(73 \%)$ and mostly had secondary (34.2\%) and vocational (31.9\%) education. More than half of the 
respondents were married (55\%) and more than three quarters of the respondents lived with their families $(77.5 \%)$ (Table 1$)$.

Table 1. Sociodemographic characteristics of the study patients.

\begin{tabular}{|c|c|c|c|}
\hline \multicolumn{2}{|c|}{ Analyzed Parameters } & \multirow{3}{*}{$\begin{array}{c}n=342 \\
205 \\
137\end{array}$} & \multirow{3}{*}{$\begin{array}{l}\% \\
60 \\
40\end{array}$} \\
\hline & Female $(n=205)$ & & \\
\hline Sex & Male $(n=137)$ & & \\
\hline \multirow{7}{*}{ Age } & 18-30 years & 1 & 0.3 \\
\hline & $31-40$ years & 6 & 1.8 \\
\hline & $41-50$ years & 12 & 3.5 \\
\hline & $51-60$ years & 65 & 19.1 \\
\hline & $61-70$ years & 131 & 38.5 \\
\hline & 71-79 years & 110 & 31.8 \\
\hline & 80 years and older & 17 & 5 \\
\hline \multirow{4}{*}{ Place of residence } & Rural area & 92 & 27 \\
\hline & City $10-100,000$ citizens & 113 & 33 \\
\hline & Town $100-500,000$ citizens & 92 & 27 \\
\hline & Town $>500,000$ citizens & 45 & 13 \\
\hline \multirow{4}{*}{ Marital status } & Single & 17 & 5 \\
\hline & Married & 189 & 55 \\
\hline & Non-marital relationship & 6 & 1.8 \\
\hline & Divorced or widowed & 130 & 38.2 \\
\hline \multirow{6}{*}{ Education } & Primary & 65 & 19 \\
\hline & Lower Secondary & 1 & 0.3 \\
\hline & Secondary & 117 & 34.2 \\
\hline & Vocational & 109 & 31.9 \\
\hline & Higher vocational/Bachelor & 6 & 1.7 \\
\hline & Higher & 44 & 12.8 \\
\hline \multirow{4}{*}{ Professional status } & Professionally active & 11 & 3.2 \\
\hline & Does not work & 33 & 9.6 \\
\hline & Retirement & 208 & 60.8 \\
\hline & Pension & 90 & 26.4 \\
\hline \multirow{2}{*}{ Housing situation } & Lives alone & 77 & 22.5 \\
\hline & Lives with his or her family & 265 & 77.5 \\
\hline \multirow{5}{*}{ Financial status } & Very good & 6 & 1.8 \\
\hline & Good & 85 & 24.9 \\
\hline & Average & 207 & 60.5 \\
\hline & Bad & 36 & 10.5 \\
\hline & Very bad & 8 & 2.3 \\
\hline
\end{tabular}

In the clinical assessment, the largest group of patients was those with malignant neoplasms of digestive organs $(24.3 \%)$, breast cancer $(17.3 \%)$, and malignant neoplasms of respiratory organs $(16.7 \%)$. The number of patients without cancer was very small (3.5\%). More than half of the patients $(67.6 \%)$ had been diagnosed between one and five years earlier, the next group of patients were those diagnosed more than five years earlier (18.7\%). More than half of the patients $(56.7 \%)$ had been in palliative care for one to five years (Table 2).

A prospective study was conducted using a diagnostic survey method with the use of a generic EuroQol-5 Dimension EQ-5D-3L health and quality of life assessment questionnaire and a questionnaire developed by the researchers, which included a few questions about the patient's quality of sexual life.

EuroQol-5 Dimension EQ-5D-3L provides an assessment of five domains and a selfassessment of general health at the time of the test. The descriptive part of the questionnaire included five domains, such as mobility, self-care, usual daily activities, pain/discomfort, and anxiety/depression. A simpler version with three levels of evaluation was chosen 
for the study: no problems, moderate problems, and significant problems. The second part of the questionnaire was a visual analogue scale (EQ-VAS, EuroQol Visual Analogue Scale), describing general health from 0 to 100 (where 0 was the point indicating the worst imaginable condition and 100 was the best imaginable condition) $[5,6]$.

Table 2. Clinical characteristics of the study patients.

\begin{tabular}{|c|c|c|}
\hline Diagnosis Qualifying for Palliative Care & $n=342$ & $\%$ \\
\hline Malignant neoplasms of lip, oral cavity, and pharynx (C00-C14) & 10 & 2.9 \\
\hline Malignant neoplasms of digestive organs (C15-C26) & 83 & 24.3 \\
\hline Malignant neoplasms of respiratory and intrathoracic organs (C30-C39) & 57 & 16.7 \\
\hline Malignant neoplasm of bone and articular cartilage & 3 & 0.9 \\
\hline Melanoma and other malignant neoplasms of skin (C43-C44) & 4 & 1.2 \\
\hline Breast cancer & 59 & 17.3 \\
\hline Malignant neoplasms of female genital organs (C51-C58) & 27 & 7.9 \\
\hline Malignant neoplasms of male genital organs (C60-C63) & 28 & 8.2 \\
\hline Malignant neoplasms of urinary tract (C64-C68) & 26 & 7.6 \\
\hline $\begin{array}{l}\text { Malignant neoplasms of eye, brain, and other parts of central nervous } \\
\text { system (C69-C72) }\end{array}$ & 6 & 1.8 \\
\hline $\begin{array}{l}\text { Malignant neoplasms of ill-defined, secondary and unspecified } \\
\text { sites (C76-C80) }\end{array}$ & 11 & 3.2 \\
\hline $\begin{array}{c}\text { Malignant neoplasms, stated or presumed to be primary, of lymphoid, } \\
\text { hematopoietic, and related tissue (C81-C96) }\end{array}$ & 10 & 2.9 \\
\hline Neoplasms of uncertain or unknown behavior, (D37-D48) & 6 & 1.8 \\
\hline Other non-cancerous diseases & 12 & 3.5 \\
\hline Clinical data & $n$ & $\%$ \\
\hline Time since diagnosis less than 6 months & 27 & 7.9 \\
\hline 6 to 12 months & 20 & 5.8 \\
\hline 1 to 5 years & 231 & 67.6 \\
\hline over 5 years & 64 & 18.7 \\
\hline Time of receiving palliative care less than 6 months & 57 & 16.7 \\
\hline 6 to 12 months & 88 & 25.7 \\
\hline 1 to 5 years & 194 & 56.7 \\
\hline over 5 years & 3 & 0.9 \\
\hline Methods of treatment surgery & 172 & 52.4 \\
\hline radiotherapy & 168 & 51.2 \\
\hline chemotherapy & 225 & 68.6 \\
\hline hormone therapy & 55 & 16.8 \\
\hline no treatment & 18 & 5.5 \\
\hline
\end{tabular}

The results were statistically analyzed using IBM SPSS program. The nature of the distributions of the variables was determined using the Kolmogorov-Smirnov test. All analyzed variables showed distribution deviating from normal distribution. Therefore, non-parametric tests were used for further analyses. Significance of differences in mean (average) scores between groups was assessed using descriptive statistics and MannWhitney U tests (for comparisons of two groups) and Kruskal-Wallis tests (for three or more groups). For all comparisons, where statistically significant differences were demonstrated, error bars were plotted with a marked $95 \%$ confidence interval. Correlation analysis was performed using Spearman correlation coefficient along with significance test. The limit of statistical significance, below which differences were considered statistically significant, was $p=0.05$. 


\section{Results}

The assessment of health status and quality of life of the study patients, conducted on the basis of the analysis of responses to questions of the EuroQol EQ-5D-3L questionnaire showed that the highest (least favorable) mean scores were indicated by patients in the domain of performing usual daily activities, which had a mean value of $2.03(\mathrm{SD} \pm 0.656)$ (Table 3).

Table 3. Mean values of quality of life dimensions in the study patients.

\begin{tabular}{ccc}
\hline & Dimension EQ-5D-3L & Mean Value \pm SD \\
\hline 1. & Mobility & $1.93 \pm 0.649$ \\
\cline { 2 - 3 } 2. & Self-Care & $1.82 \pm 0.703$ \\
\cline { 2 - 3 } 3. & Usual Activities & $2.03 \pm 0.656$ \\
\cline { 3 - 3 } 4. & Pain/Discomfort & $1.93 \pm 0.490$ \\
\cline { 2 - 3 } 5. & Anxiety/Depression & $1.83 \pm 0.524$ \\
\hline
\end{tabular}

Patients' quality of life, as measured by the EQ-5D-3L questionnaire, was reduced in all patients. The least favorable parameters (moderate level) reported by study patients most frequently were:

- $\quad$ pain and discomfort (75.7\%);

- $\quad$ anxiety and depression (69.6\%);

- mobility (57.6\%);

- $\quad$ performing usual daily activities (57.3\%).

At the level of significant problems, patients most frequently indicated difficulty in performing ordinary daily activities $(22.8 \%)$ and least frequently anxiety and depression (7\%) (Table 4).

Table 4. Assessment of patients' quality of life based on EQ-5D-3L questionnaire.

\begin{tabular}{|c|c|c|c|c|c|c|c|c|}
\hline & $\begin{array}{l}\text { Domains: } \\
\text { EQ-5D-3L }\end{array}$ & $n=342$ & Mobility & Self-Care & $\begin{array}{c}\text { Usual } \\
\text { Activities }\end{array}$ & $\begin{array}{c}\text { Pain/ } \\
\text { Discomfort }\end{array}$ & $\begin{array}{c}\text { Anxiety/ } \\
\text { Depression }\end{array}$ & Total \\
\hline Level 1 & No problems & $\begin{array}{c}n \\
(\%)\end{array}$ & $\begin{array}{c}85 \\
(24.9)\end{array}$ & $\begin{array}{c}119 \\
(34.8)\end{array}$ & $\begin{array}{c}68 \\
(19.9)\end{array}$ & $\begin{array}{c}53 \\
(15.5)\end{array}$ & $\begin{array}{c}80 \\
(23.4)\end{array}$ & $\begin{array}{c}405 \\
(118.5)\end{array}$ \\
\hline Level 2 & Moderate problems & $\begin{array}{c}n \\
(\%) \\
(\%)\end{array}$ & $\begin{array}{c}197 \\
(57.6)\end{array}$ & $\begin{array}{l}164 \\
(48)\end{array}$ & $\begin{array}{c}196 \\
(57.3)\end{array}$ & $\begin{array}{c}259 \\
(75.7) \\
\end{array}$ & $\begin{array}{c}238 \\
(69.6)\end{array}$ & $\begin{array}{c}1054 \\
(308.2)\end{array}$ \\
\hline Level 3 & Significant problems & $\begin{array}{c}n \\
(\%)\end{array}$ & $\begin{array}{c}60 \\
(17.5)\end{array}$ & $\begin{array}{c}59 \\
(17.2)\end{array}$ & $\begin{array}{c}78 \\
(22.8)\end{array}$ & $\begin{array}{c}30 \\
(8.8)\end{array}$ & $\begin{array}{c}24 \\
(7.0)\end{array}$ & $\begin{array}{c}251 \\
(73.3)\end{array}$ \\
\hline & Total & $n(\%)$ & & & $342(100)$ & & & $1710(500)$ \\
\hline
\end{tabular}

On the day of the study, 341 patients assessed their general health using the EQ-5D-3LEQ VAS scale. The analysis showed that on the EQ-VAS scale (0 to 100), patients described their current general condition as moderate (50.85 \pm 19.244$)$ (Figure 1$)$.

The questionnaire developed by the authors included questions about the assessment of the study patients' quality of sexual life (results were obtained from $281(82 \%)$ respondents), the level of help in identifying and solving sexual problems by the staff of the palliative care team $(291(85 \%)$ responses), palliative care team members, who were most helpful in identifying and solving problems (only $34(10 \%)$ responses), which may indicate the difficulty in answering questions about sexual life.

The quality of sexual life after the diagnosis in more than half of the study patients $(56.9 \%)$ had worsened, especially for men $(71.7 \%)$. The results are statistically significant. However, in the opinion of less than half of the respondents $(40.6 \%)$ it had not changed. Almost half of the respondents $(47.4 \%)$ felt that the palliative care team did not recognize 
or address their sexual concerns. Only $4.5 \%$ of respondents claimed they received such assistance and $48.1 \%$ had no opinion. Patients identified nurses $(47.1 \%)$ and physicians $(44.1 \%)$ as the members of the palliative care team who were most helpful in identifying and addressing sexual concerns. Only three women indicated a psychologist (Table 5).

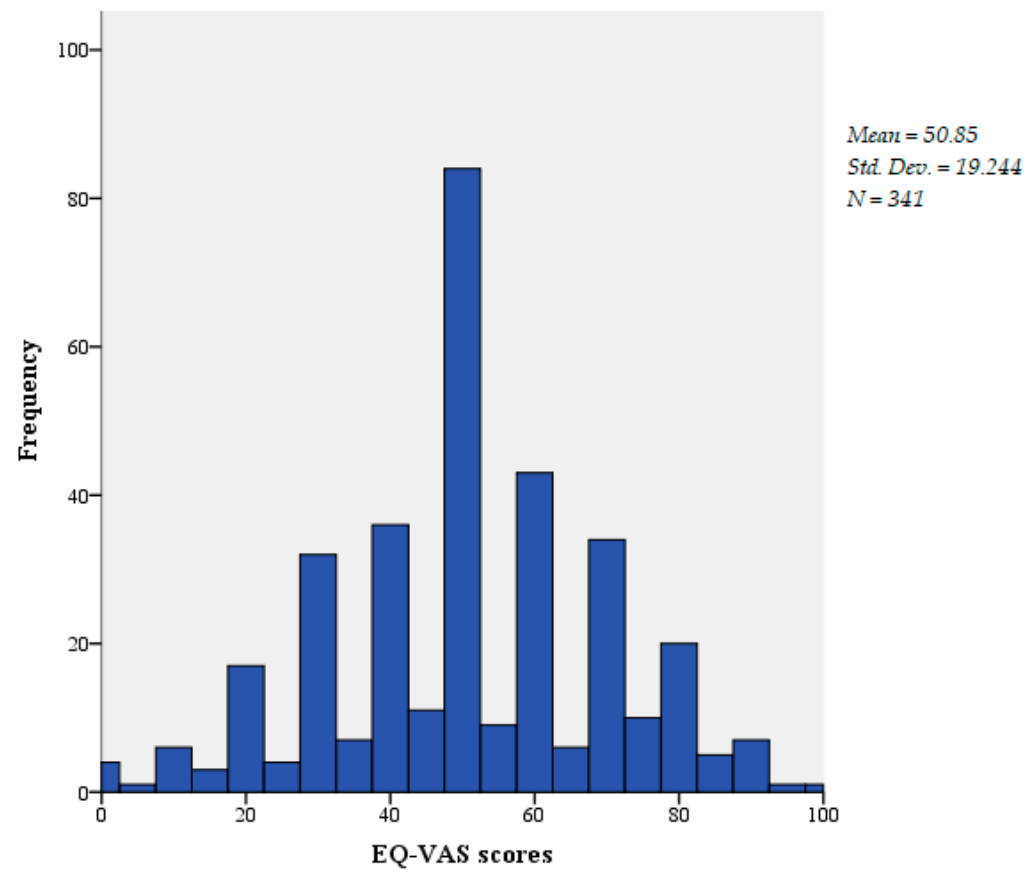

Figure 1. Frequency distribution of general health status on the EQ VAS-EQ-5D-3L scale.

Table 5. Assessment of the quality of sexual life of patients receiving palliative care.

\begin{tabular}{|c|c|c|c|c|c|}
\hline \multirow{2}{*}{\multicolumn{3}{|c|}{ Analyzed Variables }} & \multicolumn{2}{|c|}{ Sex } & \multirow{3}{*}{$\begin{array}{l}\text { Total } \\
7(2.5)\end{array}$} \\
\hline & & & Female & Male & \\
\hline \multirow{3}{*}{$\begin{array}{c}\text { Did the quality of your sex } \\
\text { life change after } \\
\text { the diagnosis? }\end{array}$} & Yes, for better & $n(\%)$ & $4(2.5)$ & $3(2.5)$ & \\
\hline & Yes, for worse & $n(\%)$ & $74(46.0)$ & $86(71.7)$ & $160(56.9)$ \\
\hline & It has not changed & $n(\%)$ & $83(51.6)$ & $31(25.8)$ & $114(40.6)$ \\
\hline \multicolumn{6}{|c|}{ Pearson's chi-square test: $19.188 ; p=0.000$} \\
\hline \multirow{3}{*}{$\begin{array}{l}\text { Did the palliative care team } \\
\text { help you to recognize and } \\
\text { solve sexual problems? }\end{array}$} & Yes & $n(\%)$ & $9(5.3)$ & $4(3.3)$ & $13(4.5)$ \\
\hline & No & $n(\%)$ & 79 (46.7) & $59(48.4)$ & $138(47.4)$ \\
\hline & I have no opinion & $n(\%)$ & $81(47.9)$ & $59(48.4)$ & $140(48.1)$ \\
\hline \multicolumn{6}{|c|}{ Pearson's chi-square test: $0.706 ; p=0.703$} \\
\hline \multirow{3}{*}{$\begin{array}{l}\text { Indicate which member of } \\
\text { the palliative care team has } \\
\text { been most helpful }\end{array}$} & Doctor & $n(\%)$ & $9(37.5)$ & $6(60.0)$ & $15(44.1)$ \\
\hline & Nurse & $n(\%)$ & $12(50.0)$ & $4(40.0)$ & $16(47.1)$ \\
\hline & Psychologist & $n(\%)$ & $3(12.5)$ & $0(0.0)$ & $3(8.8)$ \\
\hline
\end{tabular}

Pearson's chi-square test: $2.210 ; p=0.331$.

\section{Discussion}

Palliative care objectives including assessment of patient needs and functioning help to provide adequate support and facilitate communication regarding the choice of therapies and treatments. Systematic assessment of patients' quality of life, including their sex life, also allows recognition of future events that may be meaningful and unique to the patient. However, measuring quality of life in itself is insufficient and efforts should be made to improve the quality of life of terminally ill patients in all its dimensions [9]. The 
lowest mean values of the quality of life dimensions in the EQ-5D-3L were observed for performing ordinary daily activities, and the most frequently reported symptoms were pain, discomfort, and anxiety and depression.

Although the need for sexual activity decreases with age, and the problems confirmed in the quality of life study regarding the higher prevalence of symptoms such as pain and anxiety negatively affect patients' daily functioning, maintaining patients' sexuality and sexual intimacy has many positive implications for their physical and psychosocial well-being $[8,10]$. The above presented results are, to the best of the authors' knowledge, the first, but still very preliminary and general, concerning the problem of sexuality in the population of Polish patients receiving palliative care. Poland, with a very well developed network of palliative care home services, can be viewed as a pattern for Eastern and Central European countries, so the problems of Polish patients are possibly reflecting many problems of patients from that part of the world, especially in the field of sexual problems, which are almost a taboo in Poland. It was shown that sexual life of more than half of the study patients changed for the worse after diagnosis. Noteworthy is the significantly higher percentage of men compared to women (71.7 vs. $46.0 \%$ ) who expressed the above presented opinion. Almost half of the respondents felt that the palliative care team staff did not recognize or address these problems. Most patients with advanced diseases do not report satisfaction with their sex life [11]. Patients may adopt different attitudes and either view their sexuality as a way to enhance their emotional connection or diminish and downplay the importance of physicality and intimacy [12]. In a study by Bond et al., more than half of advanced stage cancer patients were not sexually active in the past month, despite a high frequency of desire for sexual intimacy. More than half of the patients reported that their physical condition or treatment affected the deterioration of their sex life. Of these, more than half indicated a lack of help in addressing sexual problems from health care professionals. In addition, older patients are less likely to report sexual problems than younger patients $[13,14]$. Similar conclusions were formulated by Gleeson and Hazell who found that most healthcare professionals do not routinely assess the sexual well-being of patients receiving palliative care. The most common reasons for non-assessment are fear, lack of knowledge about specialist services to which patients may be referred, and lack of access to assessment tools. Health professionals also indicated a need for support and training in this area $[15,16]$. Additionally, common reasons reported by medical staff were lack of time, prioritizing disease management over conversations about sexual health, or lack of understanding that adults in the final stages of chronic illness and in older age may still value their sexuality [7,16-18]. Numerous studies also indicated difficulties in engaging in conversations about sexuality, and poor understanding of patient concerns. $[19,20]$. Interestingly, in most situations, patients, especially older patients, expect the initiative to start conversations about sexuality and intimacy to be taken by medical staff $[17,21]$. An additional problem, apart from the lack of proper knowledge or staff training on sexual health problems of patients undergoing palliative care, is the lack of tools available in the Polish language (e.g., corresponding to the Brief Sexual Symptom checklist or Sexual Health: Your Needs after Cancer), which would allow for a simple conduct of such a conversation highlighting the most important issues from both patient and medical point of view. Only 34 study patients (less than $10 \%$ of total respondents) identified any member of the palliative care team who helped/assisted in any way with sexuality and intimacy issues. Mostly they were nurses and doctors. Only three people mentioned a psychologist.

The study results are limited by a lack of more evidence of patients' sexual activity, sexual function, and sexual satisfaction and future studies are required, using much more detailed questionnaires. However, since sexuality is considered to be one of the most important taboos in Polish society (especially in the palliative care patients population) it will be a difficult and very sensitive task. On the other hand, lacking the relevant publications regarding sexuality issues of palliative care patients in Poland and culturally close countries, this study takes a step forward and makes a contribution to highlight the 
problem of sexual health in palliative care patients. Additionally, the authors are planning to make a follow up research focusing strictly on sexual life problems of the palliative care patients' population. As was previously mentioned, this pilot study was only a part of a more extensive one on quality of life (two validated questionnaires), disease acceptance (one validated questionnaire), and corresponding issues including sexuality (questionnaire developed by authors). It was time and strength consuming for the patients to answer all questions. Limiting it to sexual issues questionnaires only will allow the researchers to spend more time introducing and opening up the patients about these problems. To maintain the cohesiveness of data, the authors are planning to proceed the surveys only at three to four sites (at least initially) with a small group of researchers including physicians, nurses, and psychologists. The frequent group meetings are being planned also to discuss all problems and share potential solutions regarding the study.

\section{Conclusions}

Sexual health assessment, choice of practices, and methods of educating and counseling patients and their partners should be an integral part of any clinical practice, including palliative care. Members of the team should receive training in talking with patients about their sex life, needs, and expectations and they should have knowledge about available options for obtaining specialized sexological care.

It is necessary to prepare and validate simple tools that will facilitate the initiation of appropriate communication between patients and members of the medical staff.

It will be important to conduct more detailed and targeted research on sexuality and intimacy in the Polish population of palliative care patients in order to adequately target the help and to improve the quality of patients' lives.

Author Contributions: Conceptualization, M.J., I.K. and V.S.-P.; methodology, M.J., I.K. and V.S.-P.; validation M.J., I.K. and V.S.-P.; formal analysis, M.J., I.K. and V.S.-P.; investigation, M.J. and I.K.; writing—original draft preparation, M.J., I.K., Z.J. and V.S.-P.; writing—review and editing, M.J., I.K., Z.J. and V.S.-P. All authors have read and agreed to the published version of the manuscript.

Funding: This research received no external funding.

Institutional Review Board Statement: The study was conducted according to the guidelines of the Declaration of Helsinki, and approved by the Ethics Committee of Silesian Medical University in Katowice (protocol code NNW/0022/KB/141/17, date of approval 30 May 2017).

Informed Consent Statement: Informed consent was obtained from all subjects involved in the study.

Data Availability Statement: The data presented in this study are available on request from the corresponding author. The data are not publicly available due to privacy and ethical restrictions.

Conflicts of Interest: The authors declare no conflict of interest.

\section{References}

1. Ciałkowska-Rysz, A. An Appraisal of the Situation of Palliative Care in Poland in 2018. Palliat. Med. 2019, 11, 163-169. [CrossRef]

2. Reblin, M.; Clayton, M.F.; Xu, J.; Hulett, J.M.; Latimer, S.; Donaldson, G.W.; Ellington, L. Caregiver, Patient, and Nurse Visit Communication Patterns in Cancer Home Hospice. Psychooncology 2017, 26, 2285-2293. [CrossRef] [PubMed]

3. Ghebreyesus, T.A.; Kanem, N. Defining Sexual and Reproductive Health and Rights for All. Lancet 2018, 391, 2583-2585. [CrossRef]

4. Redelman, M.J. Is There a Place for Sexuality in the Holistic Care of Patients in the Palliative Care Phase of Life? Am. J. Hosp. Palliat. Med. 2008, 25, 366-371. [CrossRef]

5. Taylor, B. Experiences of Sexuality and Intimacy in Terminal Illness: A Phenomenological Study. Palliat. Med. 2014, 28, 438-447. [CrossRef]

6. Varela, V.S.; Zhou, E.S.; Bober, S.L. Management of Sexual Problems in Cancer Patients and Survivors. Curr. Probl. Cancer 2013, 37, 319-352. [CrossRef]

7. Leung, M.W.; Goldfarb, S.; Dizon, D.S. Communication about Sexuality in Advanced Illness Aligns with a Palliative Care Approach to Patient-Centered Care. Curr. Oncol. Rep. 2016, 18, 11. [CrossRef]

8. Wang, K.; Ariello, K.; Choi, M.; Turner, A.; Wan, B.A.; Yee, C.; Rowbottom, L.; Macdonald, R.; Lam, H.; Drost, L.; et al. Sexual Healthcare for Cancer Patients Receiving Palliative Care: A Narrative Review. Ann. Palliat. Med. 2018, 7, 256-264. [CrossRef] 
9. Calman, K.C. Quality of Life in Cancer Patients-An Hypothesis. J. Med. Ethic 1984, 10, 124-127. [CrossRef]

10. Lindau, S.T.; Surawska, H.; Paice, J.; Baron, S.R. Communication about Sexuality and Intimacy in Couples Affected by Lung Cancer and their Clinical-Care Providers. Psychooncology 2011, 20, 179-185. [CrossRef]

11. Ananth, H.; Jones, L.; King, M.; Tookman, A. The Impact of Cancer on Sexual Function: A Controlled Study. Palliat. Med. 2003, 17, 202-205. [CrossRef]

12. Lemieux, L.; Kaiser, S.; Pereira, J.; Meadows, L.M. Sexuality in Palliative Care: Patient Perspectives. Palliat. Med. 2004, 18 , 630-637. [CrossRef]

13. Bond, C.B.; Jensen, P.T.; Groenvold, M.; Johnsen, A.T. Prevalence and Possible Predictors of Sexual Dysfunction and Self-Reported Needs Related to the Sexual Life of Advanced Cancer Patients. Acta Oncol. 2019, 58, 769-775. [CrossRef] [PubMed]

14. Dai, Y.; Cook, O.Y.; Yeganeh, L.; Huang, C.; Ding, J.; Johnson, C.E.; Dai, Y. Patient-Reported Barriers and Facilitators to Seeking and Accessing Support in Gynecologic and Breast Cancer Survi-vors With Sexual Problems: A Systematic Review of Qualitative and Quantitative Studies. J. Sex. Med. 2020, 17, 1326-1358. [CrossRef] [PubMed]

15. Gleeson, A.; Hazell, E. Sexual Well-Being in Cancer and Palliative Care: An Assessment of Healthcare Professionals' Current Practice and Training Needs. BMJ Support. Palliat. Care 2017, 7, 251-254. [CrossRef] [PubMed]

16. Wazqar, D.Y. Sexual Health Care in Cancer Patients: A Survey of Healthcare Providers' Knowledge, Attitudes and Barriers. J. Clin. Nurs. 2020, 29, 4239-4247. [CrossRef]

17. Malta, S.; Wallach, I. Sexuality and Ageing in Palliative Care Environments? Breaking the (Triple) Taboo. Australas. J. Ageing 2020, 39, 71-73. [CrossRef]

18. Stead, M.L.; Brown, J.M.; Fallowfield, L.; Selby, P. Lack of Communication between Healthcare Professionals and Women with Ovarian Cancer about Sexual Issues. Br. J. Cancer 2003, 88, 666-671. [CrossRef]

19. Stausmire, J.M.; Smith, H.S.; Barton, A.E. Sexuality at the End of life. Am. J. Hosp. Palliat. Med. 2004, 21, 33-39. [CrossRef] [PubMed]

20. Marwick, C. Survey Says Patients Expect Little Physician Help on Sex. JAMA 1999, 281, 2173-2174. [CrossRef] [PubMed]

21. Sporn, N.J.; Smith, K.B.; Pirl, W.F.; Lennes, I.T.; Hyland, K.A.; Park, E.R. Sexual Health Communication between Cancer Survivors and Providers: How Frequently does it Occur and Which Providers are Preferred? Psychooncology 2015, 24, 1167-1173. [CrossRef] [PubMed] 